Research Article

\title{
Supersonic Jet Noise: Main Sources and Reduction Methodologies
}

\author{
Mohammadreza Azimi * and Fathollah Ommi \\ Faculty of Engineering, Tarbiat Modares University, Aerospace Group, Tehran, Iran.
}

Received 22 June 2014; Accepted 14 July 2014

\begin{abstract}
The large velocity ratio and the presence of Shocks in the exhaust plume from low bypass engines or supersonic jetliners cause jet noise to be dominant component of overall aircraft noise, and therefore is an important issue in design of the next generation of civil supersonic transport. Jet noise reduction technology also has application in the design of highperformance tactical aircraft. Jet noise is of particular concern on aircraft carriers where it is necessary for deck crew to be in relatively close proximity to the aircraft at takeoff and landing. In this paper, a brief discussion about supersonic jet noise sources and a review of the main passive technologies employed for the reduction of supersonic jet noise are presented.
\end{abstract}

Keywords: Aviation Emissions, Aircraft Noise, Supersonic Jet Noise, Turbulent Mixing Enhancement, Mach Wave Elimination.

\section{Introduction}

Aircraft noise emissions reduction has become a driving factor for competitive aircraft design, as political and environmental laws have become more firm [1-3]. Additionally, takeoff noise reduction is a key challenge for developing future supersonic jetliners. After careful planning and testing, successful implementation of innovative jet noise reduction concepts in commercial turbofan engines and military aircraft engines may be achieved for reduction of jet noise at supersonic jet exhaust configurations [4].

Jet noise, unlike many flow phenomena, has no readily harnessed this-does-that mechanistic description at fixed global flow conditions. We have Lighthill's famous strong power-law sensitivity of radiated power to velocity ("a high power, near the eighth" [5]), but no correspondingly simple guidelines exist for what changes to make at fixed flow condition to suppress noise. The complex interplay between the jet turbulence and radiated sound, added to the underlying complexity of the turbulence itself, is the root cause of this. It is a problem of describing this complexity in a useful way.

An overexpanded jet resulting from operating a convergent-divergent nozzle at a stagnation pressure below that corresponding to the nozzle design Mach number contains a quasi-periodic shock cell structure that can persist for several diameters downstream of the nozzle exit. The constructive interference of sound waves produced by the interaction of large-scale jet disturbances with the shock waves within the shock cell structure results in broadband shock noise [6-8]. Shock noise can dominate the acoustic spectra at upstream and broadside observation angles relative to the nozzle exit. Additionally, mixing noise sources are present and are associated with large scale jet disturbances (radiating in the downstream direction) that become very effective noise sources when their phase speeds (relative to the ambient speed of sound) become supersonic

*E-mail address: m_r_azimi1991@yahoo.com

ISSN: 1791-2377 @ 2014 Kavala Institute of Technology. All rights reserved.
[9] and with fine scale turbulence5 (radiating in the upstream direction).

\section{Turbulent Mixing Noise}

Numerous experiments confirm that most large-scale turbulent mixing noise comes from the region around the end of the potential core [10-16]. This leads to noise reduction via reduction of the convective Mach number. Mixing secondary air with the primary exhaust reduces the velocity of the faster of the flows so Mach wave radiation can be reduced by surrounding the primary jet with secondary flow so that the primary eddies become subsonic with respect to the secondary flow, while ensuring that the secondary eddies are subsonic. The primary and secondary shear layers are formed between the primary and secondary potential cores and between the secondary core and the ambient fluid surrounding the jet, respectively. In the potential cores, the fluid is irrotational, and the velocity is nearly uniform and equal to the nozzle exit velocities. The shear layers work to mix the two core streams of fluid. Because of the difference in velocity between the two streams, rotational motion is induced and turbulent eddies are formed in the shear layers. At the end of the secondary core, the primary and secondary shear layers merge, marking the beginning of the intermediate region of the jet, in Fig.1. This is a very important noise generation region because the primary jet is left exposed to the ambient, and a single shear layer forms with a much higher velocity gradient than either of the two shear layers in the initial region.

In a jet with fixed exit flow conditions, reduction of the Mach number entails controlling convective velocity and controlling the medium surrounding the instability wave. The former requires some form of excitation that can change convective velocity not only at the nozzle exit but also five to twenty diameters downstream, depending on the length of the potential core. The latter scheme is more plausible as it 
involves manipulation of a secondary stream. Today all commercial aircraft engines have a secondary stream, the bypass flow.

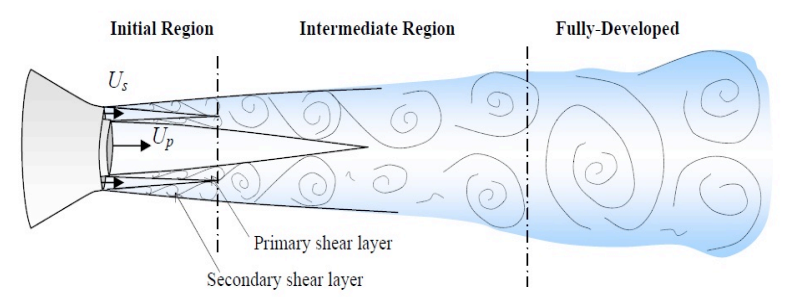

Fig. 1. Illustration of primary potential core and secondary potential core in a dual-stream jet.

In coaxial jets, as created by separate flow turbofan engines, the primary (core) jet is initially surrounded by the secondary (bypass) stream, which acts as a moving medium. In the coaxial exhaust of typical engines, the secondary stream becomes fully mixed well up-stream at the end of the primary potential core. As a result, a substantial part of the core noise source region is not covered by the secondary flow. Some noise reduction certainly occurs, but not near the levels one would expect [17]. The end of the potential core is associated with very strong turbulent fluctuations. There are two convective Mach numbers that influence noise emission: one for primary instability with respect to the secondary stream and the other for secondary instability with respect to the ambient. In non axisymmetric arrangements there is also an azimuthal dependence of the mean flow variables. Which of the two convective Mach numbers is more important depends on the volume and intensity of noise sources associated with each distribution. Various methods have been developed to reduce the generation of jet noise in aircraft.

\section{Supersonic Jet Noise reduction}

Supersonic jet noise consists of three main components: turbulent mixing noise, screech tones and broad band noise. High-speed jet noise is dominated by Mach wave emission, which arises when turbulent eddies in the jet travel with supersonic velocity relative to the surrounding medium, radiates the downstream direction and is caused by the supersonic convection of eddies relative to their surrounding medium [18-22].

Reducing the mach wave emission is a key challenge for making high-speed transports environmentally acceptable [23]. Mach wave radiation has been the subject of numerous analytical, computational, and experimental investigations [24-26]. This component of noise can be substantially removed by operating the jet at pressure matched conditions. Turbulent mixing noise, manifested as Mach wave emission in high-speed jets, is by far the most difficult noise source to be controlled. Several concepts have been developed to reduce high speed jet noise, usually involving efforts to enhance the mixing between the jet and the surrounding air. These methods reduce the length of the high velocity region of the jet where noise is generated the noise in some way [18, 27].

Supersonic jet noise reduction, however, remains a problem that has impeded the wide-scale development of supersonic air travel. Nevertheless, interest has been shown recently for the development of supersonic business aircraft, an indication that supersonic transport can have niche in market where time saving often results in crucial financial benefits. Development of a supersonic business aircraft would leverage the extensive know-how and technologies developed for military airplanes, but hinges on effective reduction of take-off noise generated by supersonic jets exhausting from the engines of such aircrafts [28]. So far, the bulk of the supersonic noise suppression effort has encompassed mixing enhancement and ejector approaches $[29,30]$ which typically lead to large and heavy power plants [31]. One may wonder if supersonic engines will follow the same evolution as subsonic engines, leading to supersonic high-bypass turbofans. The issue is not as simple, though. High bypass ratio generally causes worse, not better efficiency at supersonic speeds.

As the other main components of supersonic jet noise, screech tones and broadband noise are associated with the shock cell system in imperfectly expanded jets. Screech is a discrete tone emitted by imperfectly expanded jets. It has a significant upstream propagation component and, thus, can cause damage to the engine nozzle structure[32]. Screech is taught to be generated and sustained by a resonant feedback loop that comprises the following elements: a-sound generated by passage of eddies through shock cells bupstream propagation of the sound toward the nozzle lip, and cogeneration of new eddy by coupling of the sound with the shear-layer instability [18, 33, 34].

The second component of shock-associated noise is broadband in nature and propagates in the lateral and upstream directions. In spectral amplitude rises rapidly with frequency to a main peak and then decreases at higher frequencies. Broadband shock noise is believed to consist of acoustic waves generated by supersonically convecting, coherent, wavelike disturbances arising from the interaction of large-scale turbulent structures with the nearly periodic shock cell system of imperfectly expanded jets $[35,36]$.

It was demonstrated that addition of a secondary flow to a supersonic jet can reduce Mach wave emission when the convective velocity of the jet eddies are also subsonic values, provided that the secondary flow eddies are also subsonic with respect to the ambient $[37,38]$. This method, called mach wave elimination, achieved appreciable noise reduction in a pressure-matched jet with velocity of $920 \mathrm{~m} / \mathrm{s}$ [38]. Specifically, MWE seeks to minimize the convective mach numbers of turbulent eddies throughout the jet flow field. This includes the end of the potential core, a region of vigorous mixing and strong noise generation. In a coaxial arrangement, application of the secondary streams thus stretching the primary potential core. The end of the primary core can easily extend past the reach of the secondary flow, thus reducing the effectiveness of the technique. The eccentric arrangement has been shown to prevent significant elongation of the primary potential core [39]. It also doubles the thickness and potential core length of the secondary flow in the downward direction, thusmaking the technique very effective at suppressing mach wave emission towards the ground. More generally, the MWE results illustrate the potential for noise reduction by shaping the mean flow of the primary and secondary streams.

Experiments on Wave Elimination technique showed significant gains in noise reduction. Dimitri Papamoschou [40] investigated the noise suppression in fixed cycle, bypass ratio 3 supersonic engine. Subscale experiments showed that, relative to the mixed-flow exhaust, the coaxial separate-flow exhaust with vanes reduces the peak overall sound pressure level by $8 \mathrm{~dB}$ and the effective perceived noise level by $7 \mathrm{~dB}$ 
and the noise-equivalent specific thrust on takeoff is reduced from 490 to $390 \mathrm{~m} / \mathrm{s}$. Results also showed that by this method, $13 \mathrm{~dB}$ noise reduction with the mixed-flow exhaust and $20 \mathrm{~dB}$ quieter with the aforementioned suppression scheme, can be achieved.

Application of chevron nozzle to reduce noise radiated from heated, overexpanded, supersonic jets is another idea. Recent experiments using chevron nozzles for noise reduction on supersonic jets have focused on non-ideally expanded jets with shocks. For underexpanded jets[41, 42]. chevrons increased broadband shock noise over that of the baseline nozzle for co-flow Mach numbers less than, or equal to, 0.5. Flow-field measurements showed that the chevrons produced higher turbulence levels than the baseline nozzle near the nozzle exit and comparable shock strengths, the combined effect possibly leading to increased shock noise. In the peak jet noise direction, the chevron nozzle reduced low frequency noise relative to the baseline round nozzle. The application of chevrons to overexpanded jets [43] resulted in reduced broadband shock noise and noise reduction at all frequencies in the peak jet noise direction.
Supersonic impinging jets have also been of interest both from an applications and a fundamental fluid mechanics point of view for several decades [44-46].

\section{Conclusions}

Aircraft noise is one of the most pressing environmental problems of modern societies. Engine noise as a source of noise pollution has significant impact on the environment. On the other hand, the commercial air traffic is expected to increase substantially in the coming years, as air travel becomes more affordable worldwide. This has led to formulation of many restrictions by government agencies and airport management to place severe limits on the acceptable levels of aircraft noise near airports. Jet noise is one of the principal noise sources in aircraft. In this paper, a brief discussion about supersonic jet noise sources and a review of the main passive technologies employed for the reduction of supersonic jet noise are presented.

\section{References}

1. Mofid Gorji-Bandpy, Mohammadreza Azimi*, Airframe Noise Sources and Reduction Technologies in Aircraft, 2012, Noise and Vibration Worldwide, Vol.43, No.9, pp.29-36.

2. M. Gorji-Bandpy, M. Azimi, 2013, Passive Techniques for fan noise reduction in new turbofan engines: review, Journal of Science and Technology Review, Vol.6, Issue.1, pp.59-61.

3. Mohammadreza Azimi*, Fathollah Ommi, Naghmeh Jamshidi, Using Acoustic Liner for Fan Noise Reduction in Modern Turbofan Engines, International Journal of Aeronautical and Space Sciences, Vol.15, Issue.1, 2014, pp.97-101.

4. Mofid Gorji-Bandpy, Mohammadreza Azimi, 2012, Technologies for jet noise reduction in turbofan engines, Aviation, Vol.16, Isuue.1, pp.25-32.

5. Lighthill, M. J., 1952, On sound generated aerodynamically, I. General Theory, Procedign of the royal society, Doi: 10.1098/rspa.1952.0060

6. Harper-Bourne, M. and Fisher, M., "The noise from shock waves in supersonic jets," Proceedings of AGARD Conference on Noise Mechanisms, AGARD, 1973.

7. Tam, C., "Stochastic model theory of broadband shock associated noise from supersonic jets," J.Sound and Vib., Vol. 116, Pt. 2, 1987, pp. $265-302$.

8. Tam, C., "Stochastic model theory of broadband shock associated noise from supersonic jets in flight," J .Sound and Vib., Vol. 151, Pt. 1, 1991, pp. 131-147.

9. Laufer, J., Schlinker, R., and Kaplan, R. E. "Experiments on supersonic jet noise," AIAA J., Vol. 14, No. 4, 1976, $489-497$.

10. Troutt, T.R.; McLaughlin, D.K. 1982, Experiments on the Flow and Acoustic properties of a Moderate Reynolds Number Supersonic Jet, " Journal ofFluid Mechanics, Vol. 116, pp. 123-156.

11. Mikkelsen, K.;Bridges, J. 2000, Acoustics and thrust of separate flow exhaust nozzles with mixing devices for high-Bypass-ratio engines, AIAA Paper2000-1961.

12. Panda, J.; Zaman, K.B.M.Q. 2001, Density Fluctuation in Asymmetric Nozzle Plumes and Correlation with Far Field Noise, AIAA-2001-0378.

13. Panda, J.; Seasholtz, R.G. 2002, Experimental Investigation of Density Fluctuations in High-Speed Jets and Correlation with Generated Noise Journal ofFluid Mechanics, vol.450, pp.97-130.

14. Hileman, J.; Samimy, M. 2001, Turbulence Structures and the Acoustic Far Field of a Mach 1.3 Jet, AIAA Journal, vol.39, No.9, pp.1716-1727.

15. Narayanan, S.; Barber, T.J.; Polak, D.R. 2002, High subsonic Jet Experiments: Turbulence and Noise Generation Studies, AIAA Journal, vo.40,No.3, pp.430-437.

16. McLaughlin, D.K.; Morrison, G.D.; Troutt, T.R. 1975, Experiments on the Instability Waves in a Supersonic Jet and their Acoustic Radiation," Journal of Fluid Mechanics, Vol. 69, No. 11, pp. 73-95.
17. Papamoschou, D. 2002, Noise Suppression in Moderate-Speed Multistream Jets,8th AIAA/CEAS Aeroacoustics Conference.

18. Nielsen, P.E.; Papamoschou, D. 2009, Mean Flow - Acoustic Correlations forDual-Stream Asymmetric Jets, 47th AIAA Aerospace Sciences Meeting.

19. Tam, C. K.W. 1995, Supersonic Jet Noise, Annual Review of Fluid Mechanics,vol. 27, pp. 17-43.

20. Avital, E. J.; Sandham, N. D.; Luo, K. H. 1998, Mach Wave Radiation inMixing Layers. Part I: Analysis of the Sound Field, Theoretical andComputational Fluid Dynamics, vol.12, pp. 73-90.

21. Tam, C. K. W.; Chen, P. 1994, Turbulent Mixing Noise from SupersonicJets, AIAA Journal, vol.32, No.9, pp.1774-1780.

22. Tam, C. K.W.; Chen, P.; Seiner, J. M. 1992, Relationship BetweenInstability Waves and Noise of High-Speed Jets, AIAA Journal, vol.30, No.7,pp.1747-1752.

23. Seiner, J.M.; Krejsa, E. 1989, Supersonic jet noise and the High Speed CivilTransport, AIAA Paper 89-2358.

24. Mitchell, B.E.; Lele, S.K.; Moin, P. 1994, Direct Computation of Mach waveradiation in an axisymmetric supersonic jet, AIAA Journal, vol.35, No.10,pp.1574-1580.

25. Seiner, J.M.; Bhat, T. R. S.; Ponton, M. K. 1994, Mach Wave Emissionfrom a High-Temperature Supersonic Jet, AIAA Journal, vol.32, No. 12, pp.2345-23

26. Troutt, T.R.; McLaughlin, D.K. 1982, Experiments on the flow and AcousticProperties of a Moderate Reynolds Number Supersonic Jet, Journal of FluidMechanics, vol.116, pp.123-156.

27. Plencner, R.M. 1998, Engine Technology Challenges for the HighSpeed CivilTransport Plane, AIAA Paper No.98-2505.

28. Debiasi, M.; Papamoschou, D. 2001, Cycle analysis foe quieter supersonicturbofan engines, AIAA-2001-3749.

29. Nagamatsu, H.T.; Sheer, R.E.; Gill, M.S. 1972, Characterisics of MultitudeMultishroud supersonic jet noise suppressor, AIAA Journal, vol.10, No.3, pp.307-313.

30. Tillman,T.G.; Paterson, R.W.; Presz, W.M.; 1992, Supersonic Nozzle MixerEjector, AIAA Journal of propulsion and er, vol.8, No.2, pp.513-519.

31. Plencer, R.M. 1998, Engine technology challenges for the highspeed civiltransport plane, AIAA 98-2505.

32. Hay, J.A.; Rose, E.G. 1970, In-Flight Shock-Cell Noise, Journal of Soundand Vibration, vol.11, pp.411-420.

33. Raman, G. 1998, Advances in understanding supersonic jet screech, AIAA paper98-0279.

34. Powell, A. 1953, On the Mechanism of Chocked Jet Noise, Proceedings of thePhysical Society, London, vol.66, pp.1039-1056.

35. Tam, C. K. W. 1987, Stochastic Model Theory of Brroadband Shock AssociatedNoise from Supersonic Jets, Journal of Sound and Vibration, vol.116, No.2,pp.265-302. 
36. Tam, C. K. W.; Tanna, H.K. 1982, Shock Associated Noise of Suresonic Jetsfrom Convergent-Divergent Nozzles, Journal of Sound and Vibration, vol.81,No.3, pp.337-358.

37. Papamoschou, D. 1997, Mach wave Elimination from Supersonic Jets, AIAAJournal, vol.35, No.10, pp.1604-1611.

38. Papamoschou, D.; Debiasi, M. 1999, Noise Measurements in Supersonic JetsTreated with the Mach Wave Elimination Method, AIAA Journal, vol.37, No.2,pp.154-160.

39. Murakami, E.; Papamoschou, D. 2002, Mean Flow Development in Dual-Stream Compressible Jets, AIAA Journal, vol.40, No.6, pp.1131-1138.

40. Papamoschou, D. 2004, Engine Cycle and Exhaust Configurations for QuietSupersonic Propulsion, Journal of Propulsion and Power, vol.20, No.2,pp.255-262.

41. Rask, O., Gutmark, E., and Martens, S. "Broadband shock associated noise suppression by chevrons," AIAA 2006-009, 2006.
42. Rask, O., Gutmark, E., and Martens, S. "Shock cell modification due to chevrons," AIAA 2007-831, 2007.

43. Martens, S. and Ludwig, H. "Jet noise reduction for high speed exhaust," Proc. Of ASME Turbo Expo 2008: Power for Land, Sea and Air, Berlin, Germany, GT2008-50455, 2008.

44. Greska, B., Krothapalli, A., Burnside, N., and Horne, W. D., Highspeed jet noise reduction using microjets on a jet engine, 2004, AIAA-2004-2969.

45. Martens, S. and Haber, L., Jet noise reduction for high speed exhaust systems,2008, GT2008-50455, Proc. Of ASME Turbo Expo 2008: Power for Land, Sea, and Air, Berlin, Germany.

46. Krothapalli, A., Venkatakrishnan, L., Elavarasan, R., and Lourenco, L., Supersonic jet noise suppression by water injection, 2000, AIAA-2000-2025. 